\title{
Effects of Tetracarpidium conophorum on Iron Overload-Induced Cardiac Toxicity in Wistar Rats
}

\author{
Silvanus Olu Innih ${ }^{1}$, Ebehiremen Bridget Iorliam² and Tracy Edoghogho Lawal ${ }^{1}$
}

Department of Anatomy, School of Basic Medical Sciences, College of Medical Sciences, University of Benin, Benin-City, Nigeria.

Department of Biochemistry, Faculty of Life Science, University of Benin, Benin-City, Nigeria.

\author{
Corresponding Author: Silvanus Olu Innih \\ silvanus.innih@uniben.edu \\ $+2347032938275$
}

Keywords: Tetracarpidium conophorum, iron (II) chloride, heart, lipid peroxidation and Wistar rat.

\begin{abstract}
This study was carried out to investigate the effects of Tetracarpidium conophorum on iron overload-induced cardiac toxicity in wistar rats. A total of 30 rats weighing between $170-245 \mathrm{~g}$ were divided into six groups (A, B, C, D, E and F) of five per group. Group A (control) was administered $1 \mathrm{ml}$ of distilled water, group B, C, D, E, and F were induced with iron (II) chloride for thirty days and treated with different doses of the extract except group B for thirty days, group F was treated with standard drugs at the same time interval, using orogastric tube. After last day of administering drugs, the rats were left for an overnight fast and then sacrificed 24 hours later. Blood tissue samples were collected through cardiac puncture and immediately transferred to EDTA sample bottles for iron level and total iron concentration tests. $2 \mathrm{ml}$ was transferred into plain sample bottles for oxidative stress test analysis. Free radical scavenging activities, lipid peroxidation, haematological indices, body and heart weight and histological studies analysis were accessed. Results shows that there was significant increase $(\mathrm{p}<0.05)$ in body weight and no significant change in organ weight. These show that Tetracarpidium conophorum extract when mildly consumed has healing effect on damages heart induced by iron (II) chloride. It also proves anti-inflammatory activity of walnut. Histological slides showed vascular ulceration, erosion and stenosis of coronary artery in group B treated with only iron (II) chloride while other groups were normal. There was no significant change in anti-oxidant enzymes activities, except glutathione peroxidase that significantly increased in group F treated with high dose of the extract. However, graded doses of Tetracarpidium conophorum and standard drug reversed the lesions induced by iron (II) choride. Tetracarpidium conophorum extract has ameliorating effects on iron (II) chloride-induced heart damage.
\end{abstract}

\section{Introduction}

Iron is a vital metal for haemoglobin synthesis of erythrocytes, cellular proliferation and oxidationreduction reactions, but excess iron accumulation causes organ dysfunction by the generation of reactive oxygen species (ROS) [1]. The metabolism of iron is regulated by several factors such as hepcidin. It is a peptide hormone that affects iron absorption in small intestine and systemic iron regulation absorbed in the ileum and jejunum [2]. Two-third of iron is composed of red blood cells (RBC) and recycled iron by $\mathrm{RBC}$ destruction, remainder is stored in ferritin /hemosiderin, while only about $1-2 \mathrm{~g}$ are absorbed in the intestinal tract and circulated in blood [3]. Iron-overload occurs in adults who have ingested iron for a prolonged period. Ahluwalia et al., [4] shows that there is relationship between body iron overload and pathogenesis of numerous degenerative diseases, as well as atherosclerosis. In addition, excessive iron has been reported to be a potent risk factor for coronary heart disease [5]. The consumption of food rich in iron and administration iron supplements to patients with cardiovascular disease (CVD) should be properly regulated [6].

Different parts of $T$. conophorum have been used ethnomedically, including the stem bark, leaves, seeds and roots for the treatment of toothache, cold, eczema, dizziness and prostate cancer. The bark is also used by locals as a laxative [7]. The seed kernel, when eaten raw, has a bitter taste and is 
considered to be a tonic and aphrodisiac [8]. The seed of T. conophorum has been used for the treatment of fibroids; the boiled seeds are also eaten to improve sperm count in men while the leaf juice is used to improve fertility in women and regulate menstrual flow [9]. They are also used by the elderly people for the treatment of constipation and flatulence [7]. The oil from the nut are used in the formulation of vulcanised oil for rubber and leather substitutes, wood varnish and stand oil [10]. There are limited literature on the health benefits of $T$. conophorum in the treatment of iron overloadinduced toxicity on the heart which necessitated the current research aimed at providing scientific information on the effects of Tetracarpidium conophorum on iron overload-induced cardiac toxicity in wistar rats.

\section{Material and Methods}

\section{Chemical and Drugs}

All chemicals, drugs and reagents used in this investigation were of analytical grade. All test drugs and reagents were freshly prepared before use. Iron (II) chloride was manufactured by Xilong Chemical Co., Ltd., No.1-3 Xilong Middle Street, Chaosan Road, Shantou City, Guadong Province, China.

\section{Plant Material and Preparation of Extract}

Raw Tetracarpidium conophorum seeds were purchased from a local market in Benin-City, Nigeria. The seeds were identified and confirmed in the Department of Plant Biology and Biotechnology, University of Benin, Edo State, Nigeria. Herbarium specimen with voucher number 222849 was deposited at herbarium of University of Benin, Benin City, Nigeria. The shells were broken and edible parts were separated and then pulverized into powder using British milling machine. The seeds were weighed and macerated in a jar with distilled water of $900 \mathrm{ml}$ for 24 hours with constant shaking and stirring. The mixture was then filtered to separate the residue from the filtrate using filter paper, funnel and conical flask. Then the filtrate was concentrated to paste level using water bathe, crucible. The crude extract was then preserved in a sample bottle inside a refrigerator. All processed were carried out at the Department of Pharmacognosy, Faculty of Pharmacy, University of Benin, Nigeria.

\section{Animal Care and Management}

Total of thirty (30) Wistar rats weighing between 170 and 245g were used for this study. The animals were housed and bred in the Animal House unit in the Department of Anatomy, University of Benin. Temperature range of $21 \pm 1^{\circ} \mathrm{C}$ with light on and off schedule, 12 hours respectively was used to maintain the animal house. Animals were acclimatized for two (2) weeks before the commencement of administration.

Management and experimental protocols were in accordance with recommendation of the PHS (Public Health Service), Public Health Service Policy on Human Care and Use of Laboratory Animals, 2002.

\section{Administration of Iron (II) Chloride}

Iron overload was induced using iron (II) chloride. $10 \mathrm{mg}$ of iron (II) chloride was dissolved in 1000 $\mathrm{ml}$ of water to make a concentration of $0.01 \mathrm{mg} / \mathrm{dl}$. The iron (II) chloride was administered orally through the use of orogastric tube. $\mathrm{LD}_{50}$ of iron (II) chloride is $500 \mathrm{mg} / \mathrm{kg}$ [11].

\section{Doses for Biological Investigation}

The doses were in groups namely low dosage, moderate dosage and high dosage at 250, 500 and $1000 \mathrm{mg} / \mathrm{kg}$ respectively. The dosage was chosen based on toxicity report that $\mathrm{LD}_{50}$ of T. conophorum is $5000 \mathrm{mg} / \mathrm{kg}$ [12].

\section{Experimental Animals}

The rats were grouped into six (6): A, B, C, D, E and F, with each group containing five (5) Wistar rats. Group A is control group and was administered $1 \mathrm{ml}$ of distilled water only. Group B was treated 
with iron (II) chloride only. Groups C, D and E were given iron (II) chloride, then treated with low $(250 \mathrm{mg} / \mathrm{kg})$, moderate $(500 \mathrm{mg} / \mathrm{kg})$ and high dosages $(1000 \mathrm{mg} / \mathrm{kg})$ of Tetracarpidium conophorum seed extract, respectively. Group F was treated with iron (II) chloride and standard drug (Atorvastatin). All administration was done by the use of orogastric tube for thirty (30) days.

Body weight of animals were taken before commencement of feeding and treatment. At exactly two weeks after acclimatization, treatment with iron(II)chloride commenced for groups B, C, D and E which lasted for thirty (30) days, after which the treatment with walnuts extract begun and also lasted for thirty (30) days. Group F was also treated with iron (II) chloride before treatment with standard drugs at same time interval.

During these periods, rats had direct access to feed (growers mash) and water ad libitum After the last day of administration, the rats were left for an overnight fast and then sacrificed 24 hours later. At sacrifice, heart was excised and immediately fixed in normal saline for tissue processing. Blood samples were collected through direct cardiac puncture with syringes into plain sample bottles and EDTA sample bottles for haematological analysis. Photomicrographic plates of the desired sections were taken, using a standard photomicrography setup viz: Olympus XSZ-107BN microscope and an attached Eakins 1080P microscopic camera.

Table 1: Experimental Design

\begin{tabular}{ll}
\hline Groups & Treatments \\
\hline A (control) & $1 \mathrm{ml}$ of distilled water \\
B (iron (II) chloride) & $2 \mathrm{ml}$ of iron (II) chloride \\
C (low dose) & $2 \mathrm{ml}$ of iron (II) chloride $+250 \mathrm{mg} / \mathrm{kg}$ of the seed extract \\
D (moderate dose) & $2 \mathrm{ml}$ of iron (II) chloride $+500 \mathrm{mg} / \mathrm{kg}$ of the seed extract \\
E (high dose) & $2 \mathrm{ml}$ of iron (II) chloride $+1000 \mathrm{mg} / \mathrm{kg}$ of the seed extract \\
F (standard drug) & $2 \mathrm{ml}$ of iron (II) chloride $+0.2 \mathrm{ml}$ of atorvastatin (standard drug) \\
\hline
\end{tabular}

\section{Antioxidant Activities and Lipid Peroxidation}

Glutathione peroxidase activity was estimated by the method of Nyman [13]. Catalase activity was determined by the method of Cohen et al., [14]. The activity of superoxide dismutase was determined according to the methods of Misra and Fridovich [15]. Malondialdehyde (MDA), one of the end products of lipid peroxidation was estimated by the method of Buege and Aust [16].

\section{Statistical Analysis}

Data were expressed as (mean \pm SEM) of six replicates and were subjected to one way analysis of variance (ANOVA) using SPSS version 10.0 and the individual comparisons were obtained by the Duncan multiple range test (DMRT). A value of $\mathrm{p}<0.05$ was considered to indicate a significant difference between groups.

\section{Results}

Effect of Tetracarpidium conophorum on body and organ weight: Table 2 showed that there were significant increases in final weights compared with initial weights in all the groups except for the control group respectively $(\mathrm{P}<0.05)$. There were no significant changes on the weight of organ (heart) in all the treated groups compared with group A respectively $(\mathrm{P}>0.05)$.

Table 2: Showing the mean values of initial and final body weight following the administration of walnut extract

\begin{tabular}{lllllllll}
\hline P a r a m e e r s & Group A & Group B & Group C & Group D & Group E & Group F \\
\hline Initial weight (g) & $182.5 \pm 14.22$ & $172.5 \pm 4.33$ & $172.5 \pm 10.51$ & $182.5 \pm 8.29$ & $173.8 \pm 6.25$ & $170.0 \pm 12.42$ \\
Final weight (g) & $188.3 \pm 6.01$ & $245.0 \pm 5.00$ & $245.0 \pm 6.71$ & $232.5 \pm 17.14$ & $227.5 \pm 5.95$ & $236.7 \pm 7.27$ \\
Heart weight (g) & $0.677 \pm 0.035$ & $0.595 \pm 0.005$ & $0.654 \pm 0.016$ & $0.595 \pm 0.041$ & $0.595 \pm 0.017$ & $0.65 \pm 0.00$ \\
P - r a l e s & $\mathrm{P}>0.05$ & $\mathrm{P}<0.05$ & $\mathrm{P}<0.05$ & $\mathrm{P}<0.05$ & $\mathrm{P}<0.05$ & $\mathrm{P}$ & $<.05$ \\
\hline
\end{tabular}

$\mathrm{P}<0.05$ indicates significant difference. 
In Table 3, there were significant increase in total concentration of iron $\left(\mathrm{Total}_{\mathrm{Fe}}^{++}\right)$in all the treated groups compared with group A (control) respectively $(\mathrm{P}<0.05)$. In addition, there were significant increase in iron level $\left(\mathrm{Fe}^{++}\right)$in all the treated groups compared with group A (control) respectively (P $<0.05)$.

Table 3: Comparing the mean values of haematological indices in treated Wistar rats.

\begin{tabular}{|c|c|c|c|c|c|c|}
\hline Parameters & Group A & Group B & Group C & Group D & Group E & Group F \\
\hline Tot a 1 & 4.73 & $258.5 \pm 34.50^{*}$ & $228.0 \pm 4.22 *$ & $259.8 \pm 24.33 *$ & $408.3 \pm 25.69^{*}$ & $617.0 \pm 107.0^{*}$ \\
\hline $\mathrm{e}$ & $23.67 \pm 0.88$ & $51.50 \pm 0.50 *$ & $40.80 \pm 0.74^{*}$ & $48.75 \pm 2.32 *$ & $87.25 \pm 14.60^{*}$ & $89.00 \pm 2.00 *$ \\
\hline
\end{tabular}

$* \mathrm{P}<0.05$ indicates significant difference in treated groups compared with the control.

The result in Table 4 shows that there was significant increase in catalase and glutathione peroxidase activities in group $\mathrm{F}$ compared with group $\mathrm{A}(\mathrm{P}<0.05)$, however, there were no significant changes in group $\mathrm{B}, \mathrm{C}, \mathrm{D}$, and group $\mathrm{E}$ compared with group $\mathrm{A}$ respectively $(\mathrm{P}>0.05)$. There was no significant change in catalase in all the treated groups compared with group $\mathrm{A}(\mathrm{P}<0.05)$. There was no significant change in the level of malonaldehyde in all the treated groups compared with group A $(\mathrm{P}<0.05)$.

Table 4 Comparing the mean values of some oxidative stress markers in Wistar rats treated with walnut extract and atorvatastin

\begin{tabular}{lllllll}
\hline Glutathione peroxidase (GPx) & $152.0 \pm 8.99$ & $160.0 \pm 34.19$ & $153.6 \pm 24.83$ & $151.1 \pm 21.18$ & $193.3 \pm 18.28$ & $202.0 \pm 6.68^{*}$ \\
\hline Sodium dismutase(SOD) & $44.10 \pm 8.50$ & $47.22 \pm 8.89$ & $45.77 \pm 5.64$ & $44.15 \pm 5.40$ & $63.51 \pm 11.12$ & $58.09 \pm 4.25$ \\
Malonaldehyde(MD A) & $36.12 \pm 3.33$ & $39.23 \pm 4.48$ & $38.46 \pm 7.58$ & $42.68 \pm 6.26$ & $47.89 \pm 5.09$ & $53.46 \pm 6.74$ \\
C a t a 1 a s e (C A T ) & $4.33 \pm 0.28$ & $3.62 \pm 1.53$ & $4.34 \pm 0.93$ & $4.22 \pm 0.48$ & $3.330 \pm 0.68$ & $2.95 \pm 0.17^{*}$ \\
\hline
\end{tabular}

$* \mathrm{P}<0.05$ indicates significant difference in treated groups compared with the control.

Histological findings indicated that increased doses of Tetracarpidium conophorum extract have ameliorating effect on the iron (II) chloride induced damages as shown in plates 3-6.

Group A

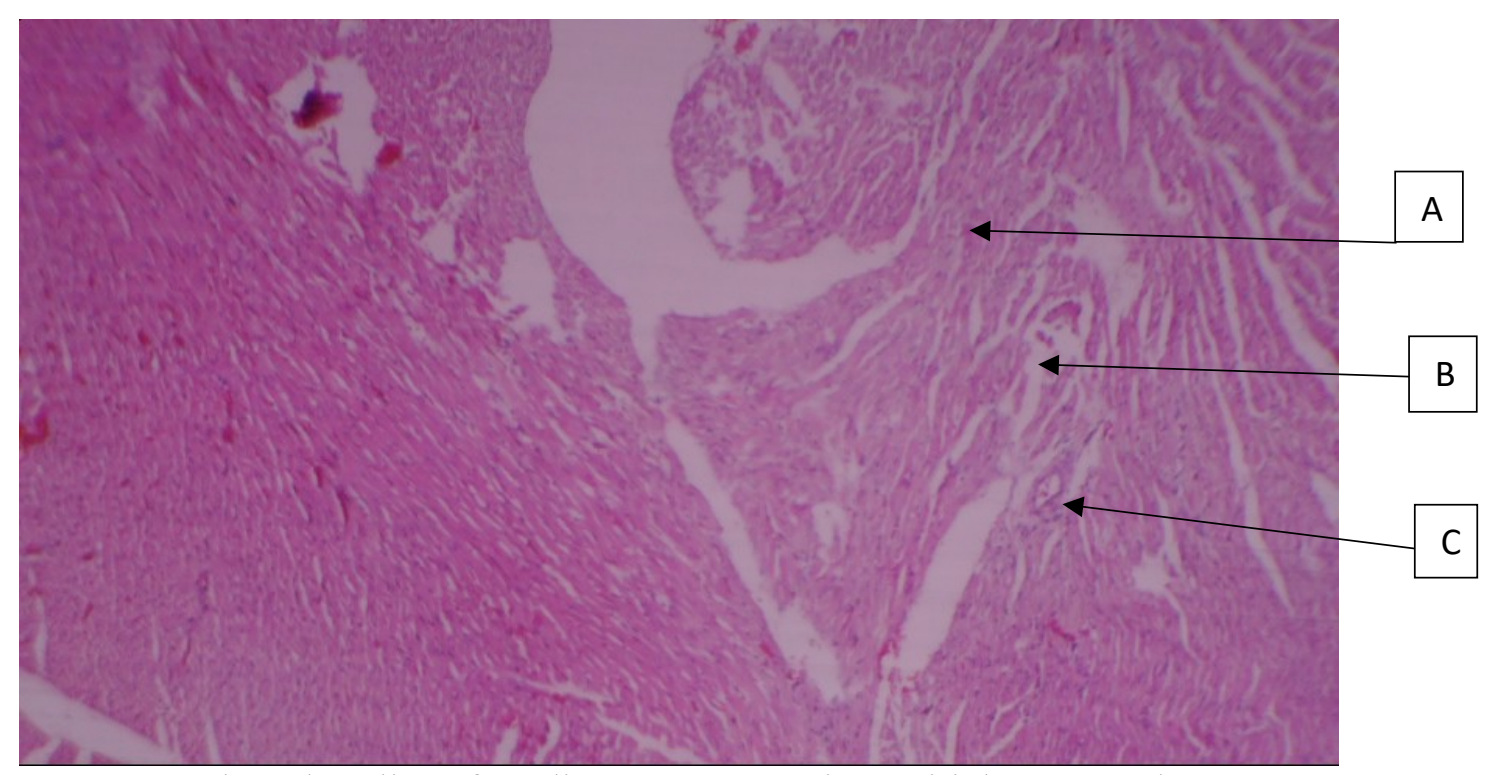

Plate 1: Heart control: A, bundles of cardiomyocytes, B, interstitial space and C, coronary artery (H\&E x 40) 
Group B

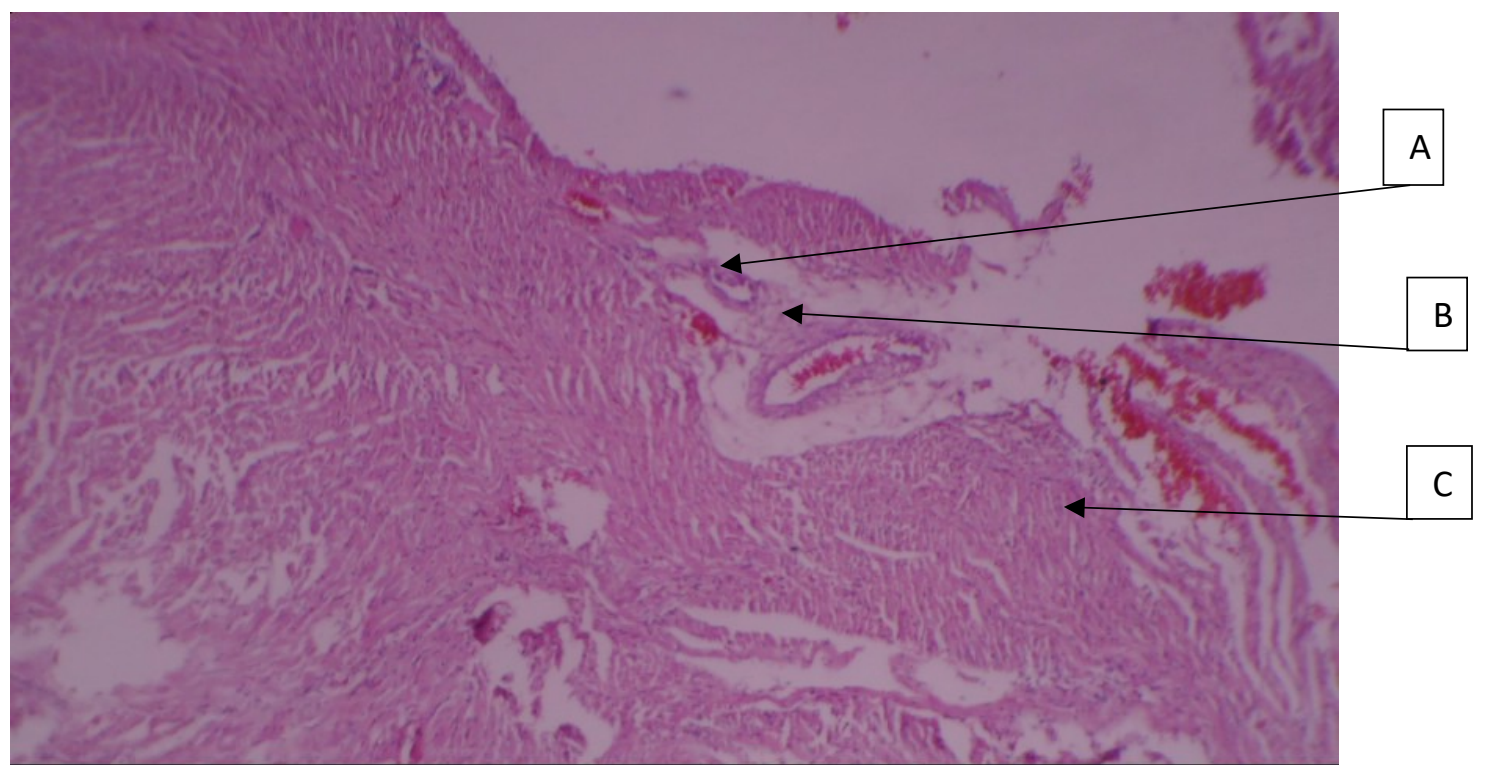

Plate 2: Rat given Iron only: A, vascular ulceration and stenosis and B, perivascular inflammatory infiltrates (H\&E x 40)

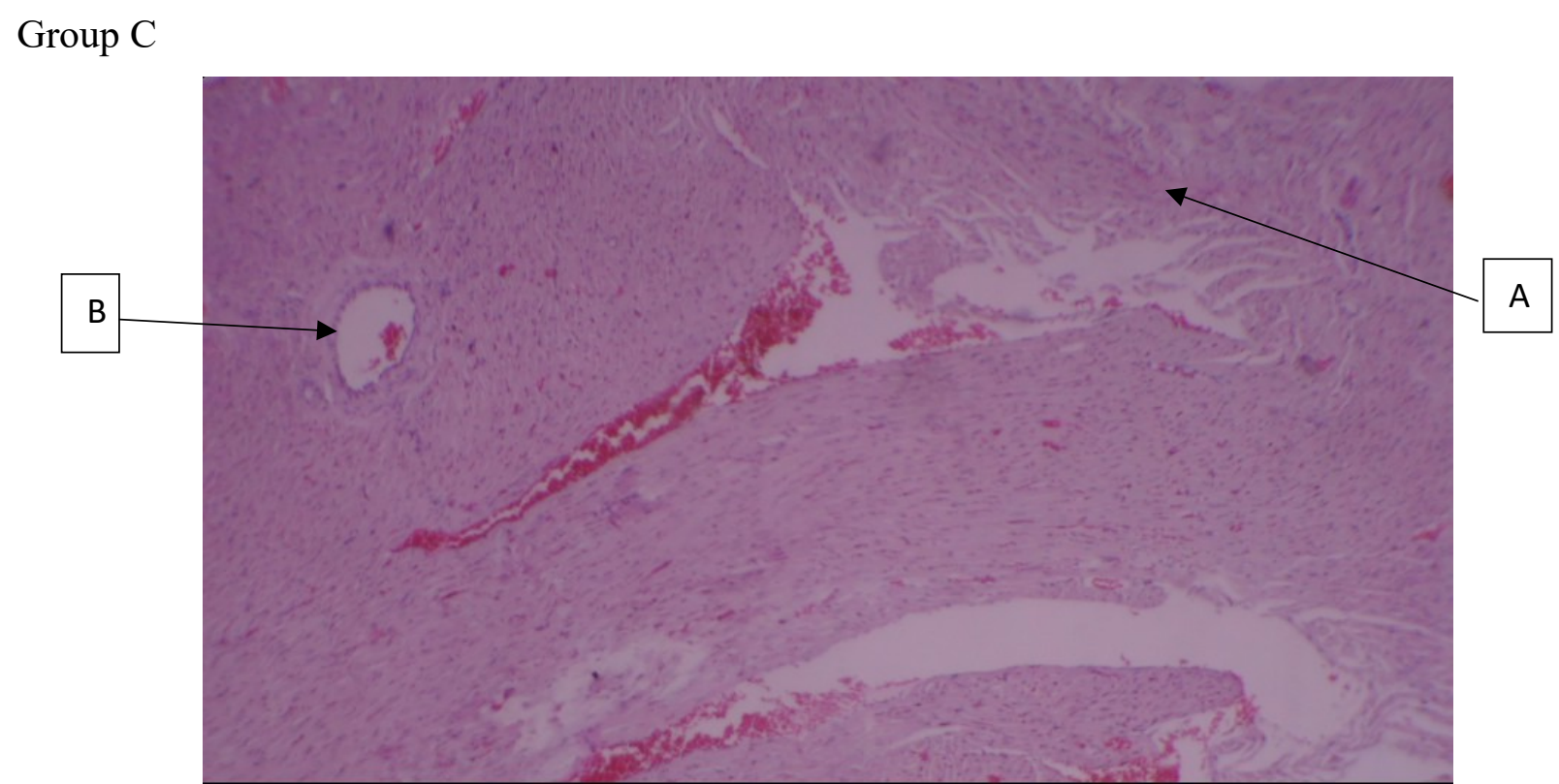

Plate 3: Rat given Iron plus low dose Extract: A, normal cardiomycytes and B, vasculature (H\&E x 40) 


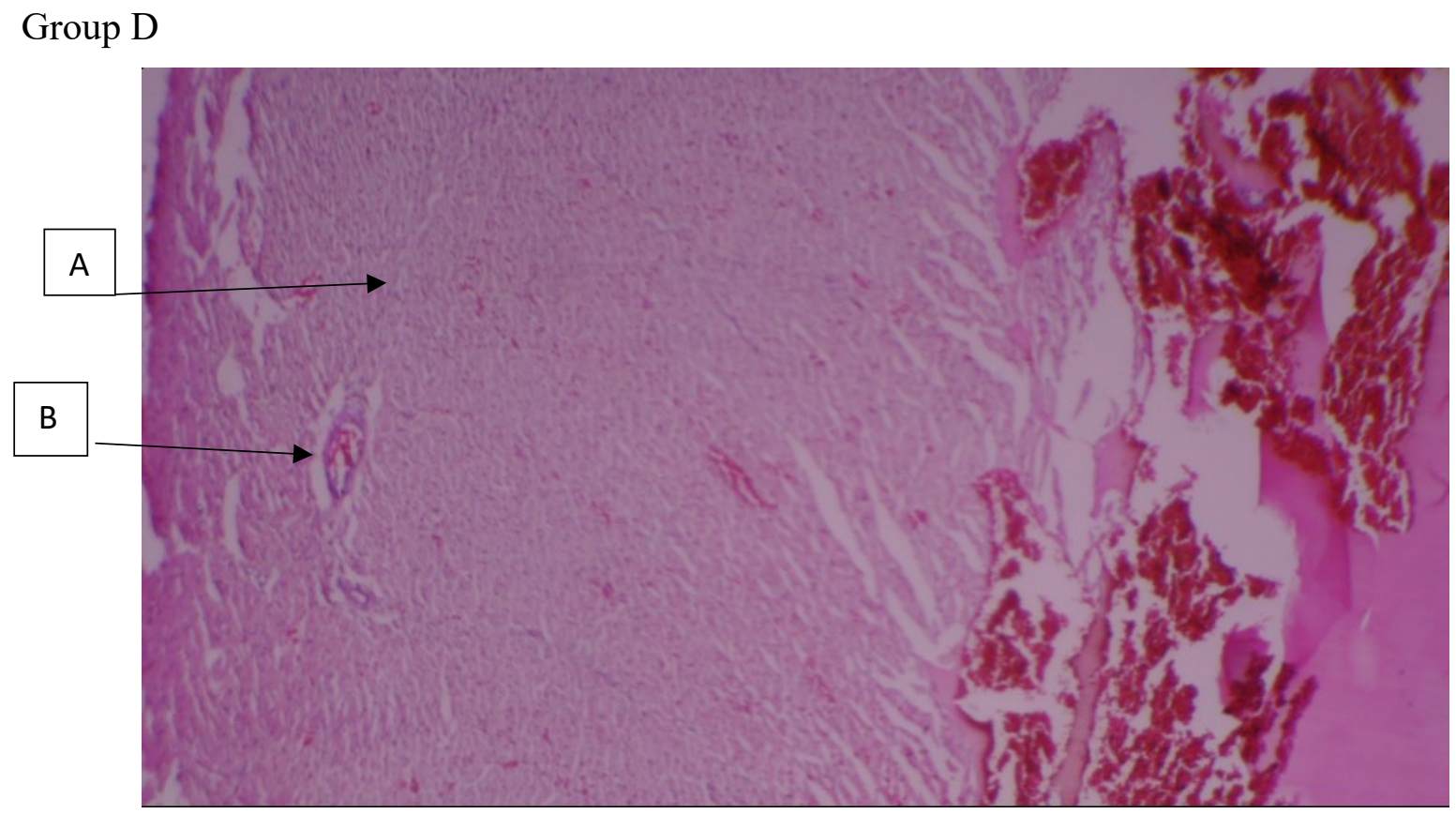

Plate 4: Rat given Iron plus moderate dose Extract: A, normal myocardiac fibres and B, vasculature (H\&E x 40)

Group E

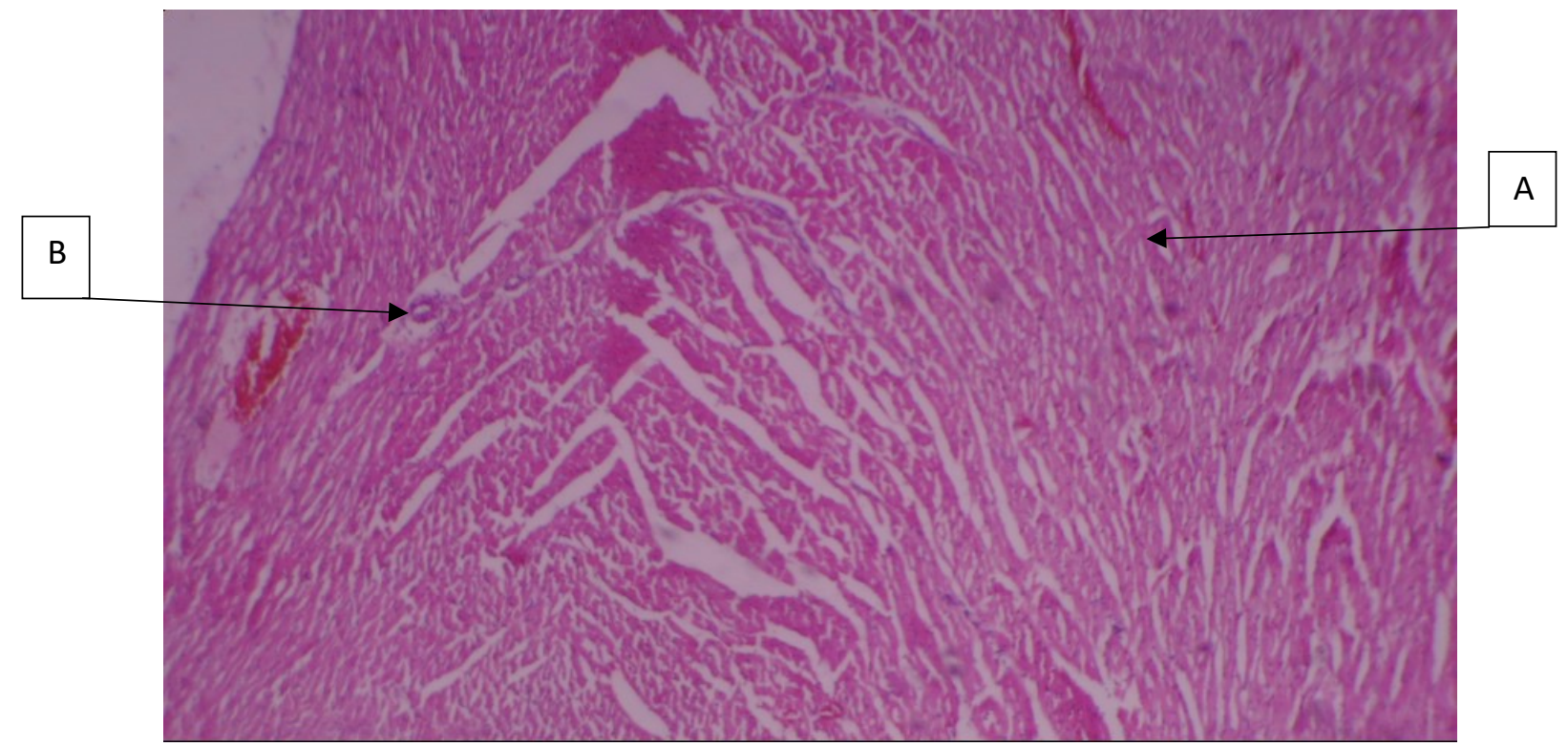

Plate 5: Rat given Iron plus high dose Extract: A, normal myocardiac fibres and B, vascular architecture (H\&E x 40) 


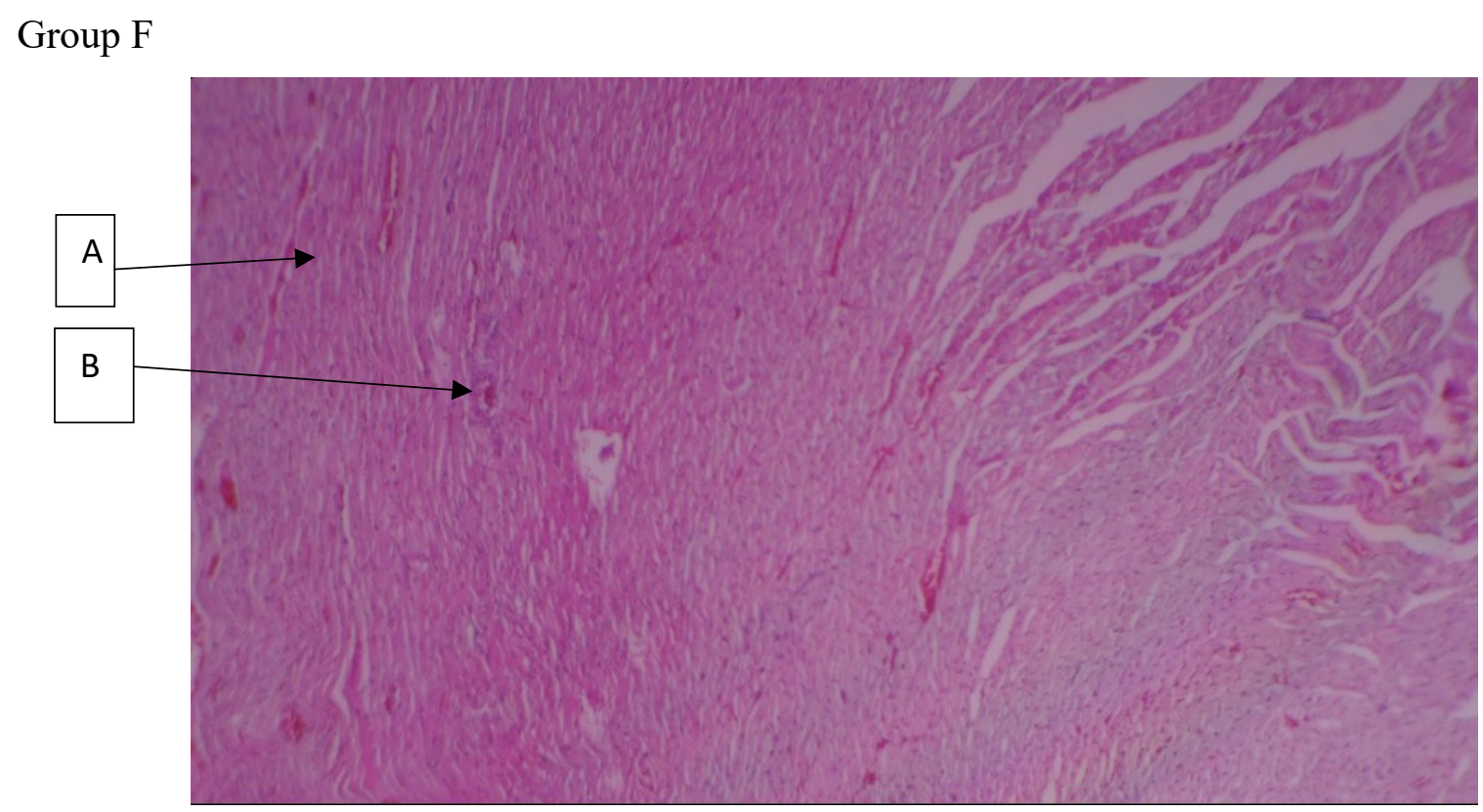

Plate 6: Rat given Iron plus standard drug: A, normal cardiomyocytes and B, vasculature

(H\&E x 40)

\section{Discussion}

Iron (II) chloride is a very toxic metallic substance known for induction of iron overload in the body [17]. Iron (II) chloride is also called ferric chloride with the chemical formula, $\mathrm{FeCl}_{2}$. It is a paramagnetic solid with a high melting point. Iron is an essential metal for cell function but excess iron accumulation causes organ dysfunction through the production of reactive oxygen species (ROS) [18]. Ahluwalia et al., also reported that iron overload results to pathogenesis of numerous degenerative diseases, such atherosclerosis [19]. In addition, excessive iron has been proposed to be a potent risk factor for coronary heart disease (CHD) especially for acute myocardial infarction (AMI) [20]. Approximately, the amount of iron that should be in the body is 3-4g [21].

However, walnut is known for several ameliorating effects but unknown for its effect on ironoverload [7]. Statistical results show there was significant difference in initial and final body weight which proves the weight gaining effect of walnut [22]. Also, there was no significant difference in organ weight which shows the anti-inflammatory effect of walnuts [23].

In total iron concentration and iron level, there was significant increase in all treatment groups compared to the control group. This result shows effect of walnut in increasing iron level of the body which is necessary for transport of oxygen throughout the body [24].

Antioxidants act as radical scavengers, inhibit lipid peroxidation and other free radical-mediated processes, this protect the human body from several diseases accredited to the reactions of radicals. Antioxidants protect the cells either by neutralizing or scavenging free radicals or by preventing the production of free radicals. Free radicals prevent antioxidant enzymes activities and initiate lipid peroxidation [25].

MDA represents an end-product of the peroxidation of polyunsaturated fatty acids and related esters within cell membranes and is currently regarded as a reliable index of oxidative tissue damage. However, there were no significant difference in the level of malonaldehyde in all the groups when compared with the control, this shows that oxidative stress sometimes may not results to cardiovascular damages [25].

The increase in some of the activities of antioxidant enzymes in the study especially in group F, may be responsible for preventing the production of free radicals that can results to cardiovascular damages. The photomicrographs for control group shows normal microscopic architecture of cardiomyocytes with interstitial spaces. In group B, that was treated with iron (II) chloride only when compared with control group, there was vascular ulceration, stenosis and perivascular inflammatory infiltrates. Group C that was treated with iron (II) chloride and low dose of walnut shows normal 
cardiomyocytes and vasculature which proves the healing effect of walnut on the damaged cells. The presence of some phytochemicals such as tannins, terpenoids and flavonoids were indicated for the cytoprotective properties as well as the wound healing activity [26]. There was also dilatation of blood vessels which is a mechanism to reduce blood pressure in the heart as it contains omega-3 called alpha-linoleic acid (ALA) [27].

Group D was administered moderate dose of Tetracarpidium conophorum extract and shows normal myocardiac fibres and vessels which also applies to group E, which was treated with high dose of Tetracarpidium conophorum extract. Group F which was given iron (II) chloride and standard drug (Atorvastatin) also shows normal cardiomyocytes but with lesser dilatation in coronary vessels.

\section{Conclusion}

The results of this study show that Tetracarpidium conophorum extract increases body weight, iron level and total iron concentration. It also has ameliorating effect on iron (II) chloride-induced heart damage.

\section{References}

[1] C.Kobayashi, T. Suda, Regulation of reactive oxygen species in stem cells and cancer stem cells. Journal of cellular physiology, 227(2) (2012).421-430.

[2] J. Beard, Systemic iron regulation. In Restless Legs Syndrome, CRC Press (2016) 75-86.

[3] E. Obeagu, et al., Iron and blood donation: A Review. International Journal of Research in Medical Sciences, 2(10) (2016).16-48.

[4] Y. Beguin, et al., Epidemiological and nonclinical studies investigating effects of iron in carcinogenesis - a critical review. Critical reviews in oncology/hematology, 89(1) (2014) 1-15.

[5] J, Salonen, et al., Donation of blood is associated with reduced risk of myocardial infarction: the Kuopio Ischaemic Heart Disease Risk Factor Study. American journal of epidemiology, 148(5) (1998) 445-451.

[6] A. Atanasov, et al., Pecan nuts: A review of reported bioactivities and health effects. Trends in Food Science and Technology, 71 (2018) 246-257.

[7] A. Ayodeji, N. Aliyu, 2018. Tetracarpidium conophorum (African walnut) Hutch. \& Dalziel: Ethnomedicinal uses and its therapeutic activities. Journal of Medicinal Plants for Economic Development, 2(1), (2018) 1-10.

[8] A. Aderounmu, F. Adeboyin, Evaluation of growth media, seed-sizes and microclimate on sproutability of (African walnut). The International Journal of Organic Agriculture Research and Development, 15 (2019) 99-107.

[9] A. Nwauzoma, M. Dappa, Ethnobotanical Studies of Port Harcourt Metropolis, Nigeria. ISRN botany, 2013.

[10] V. Oyenuga, Nigeria food and feeding stuff, University Press Ibadan, Ibadan, (1997) 1112.

[11] D. Sanchez, et al., Comparative ionomics and metabolomics in extremophile and glycophytic Lotus species under salt stress challenge the metabolic pre-adaptation hypothesis. Plant, Cell and Environment, 34(4) (2011) 605-617.

[12] C. Bassey Etim, et al., Ameliorative Effect of Aqueous Extract of Tetracarpidium Conophorum (African Walnut on Salt Induced Hypertensive Wistar Rats. American Journal of Hypertension, 5(1) (2018) 1-7.

[13] N. Nyman, Determination of glutathione peroxidase in tissue. Analytical Biochemistry. 28 (1959) 481. 
[14] D. Cohen, et al., Measurement of catalase activity in tissue extracts. Annals in Clinical Biochemistry. 34 (1970) $30-38$.

[15] H. Misra, I. Fridivich, The role of superoxide anion in the autooxidation of epinephrine and a simple assay for superoxide dismutase. Journal of Biological Chemistry. 247 (1972) $3170-$ 3179 .

[16] J. Buege, S. Aust, Microsomal lipid peroxidation. Methods in Enzymology. 52 (1978) 306.

[17] A. Gilman, et al., Goodman and Gilman's The Pharmacological Basis Of Therapeutics. 8th ed. New York, NY. Pergamon Press. (1990) 1291.

[18] S. Dixon, B. Stockwell, The role of iron and reactive oxygen species in cell death. Nature chemical biology, 10(1) (2014) 9.

[19] B. Lipinski, E. Pretorius, Iron-induced fibrin in cardiovascular disease. Current neurovascular research, 10(3) (2013) 269-274.

[20] M. Moradi, et al., Relation between the serum ferritin level and the risk for acute myocardial infarction. Journal of research in health sciences, 15(3) (2015) 147-151.

[21] T. Johnson-Wimbley, D. Graham, Diagnosis and management of iron deficiency anemia in the 21 st century. Therapeutic advances in Gastroenterology, 4(3) (2011) 177-184.

[22] R. Reiter, et al., 2013. A walnut-enriched diet reduces the growth of LNCaP human prostate cancer xenografts in nude mice. Cancer investigation, 31(6) (2013) 365-373.

[23] F. Olaniyi, et al., 'Anti-inflammatory activities of the chloroform extract of the fruit of Tetracarpidium conophorum (Mull. Arg.) (Nigeria Walnuts)', Journal of Advance in Medical and Pharmaceutical Sciences. 6(1) (2016) 1-7.

[24] S. Watson, What You Need to Know About Iron Supplements. Medical News Today, Healthline Media UK Ltd, Brighton, UK (2011)

[25] S.Yang, Erythrocyte superoxide dismutase, glutathione peroxidase, and catalase activities and risk of coronary heart disease in generally healthy women:a prospective study. American Journal of Epidemiology.180 (9) (2014) 901-908.

[26] K. Ezealisiji, et al., Anti-ulcer activity of African walnut "Tetracarpidium conophorum" nuts against gastric ulcers in rats. Asian Pacific Journal of Tropical Disease. 4(1) (2014a) 670-673.

[27] D. McNamee, Eat Walnut to Lower Blood Pressure, Medical News Today, Health line Media UK Ltd, Brighton, UK (2019). 